\title{
ORIGEN DE LA RADIODIFUSIÓN PIRATA COMERCIAL
}

\author{
Francisco José Montes Fernández \\ (Universidad Complutense de Madrid) \\ fjmontes@telefonica.net \\ Javier Sierra Sánchez \\ (Universidad San Jorge de Zaragoza) \\ jsierra@usj.es
}

\begin{abstract}
Resumen: La importancia de las estaciones piratas comerciales en el contexto europeo fue tan grande que sus emisiones hicieron cambiar toda la programación de la radiodifusión de nuestro continente, pasando a una programación basada en la música ligera. Analizaremos el origen de este fenómeno para obtener una tipología y las repercusiones que tuvo este fenómeno en los modelos radiofónicos contemporáneos.
\end{abstract}

Palabras clave: Historia de la radiodifusión en Europa, radiodifusión pirata, Reino Unido, Suecia, Dinamarca, Holanda, Francia, Radio Caroline, Radio Mi Amigo, Radio Mercur.

Abstract: The relevance of commercial pirate radio stations in Europe has been so far-reaching that its broadcasts have totally transformed all radio programming on this continent. The present article analyses the origin of this phenomenon in order to obtain a typology and see the repercussions this phenomenon has had on contemporary radio models.

Keywords: The History of Broadcasting in Europe, pirate stations, the United Kingdom, Sweden, Denmark, Holland, France, Radio Carolina, Radio Mi Amigo, Radio Mercur.

\section{DEFINICIÓN}

guilera (1985: 66) atribuye el origen de la denominación al "carácter marítimo
e ilegal de la primera emisora inglesa, al Acta ${ }^{13}$ de emisiones marítimas,
promulgada por el gobierno laborista británico, que excluía a estas radios
de la legalidad, y también al hecho de enarbolar la bandera pirata en los mástiles
de los barcos que albergaron a algunas de ellas". Jurídicamente, esto es con el
Reglamento de Radiocomunicaciones a la vista, son estaciones ilícitas y pública-
mente apátridas -es en este sentido por el que cabe denominarlas "piratas"- las
siguientes:

\footnotetext{
${ }^{13}$ Nota de los autores: Suponemos que quiere decir Ley.
} 
a) Las instaladas a bordo de barcos, aeronaves, islas artificiales y otros objetos flotantes o firmes que se encuentren fuera de los territorios nacionales (UIT, 1976: Art. $\left.7 \mathrm{n}^{\circ} 422\right)^{14}$.

b) Las que efectúen transmisiones sin señal de identificación o utilicen una señal

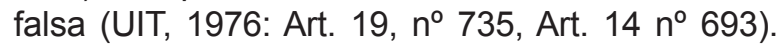

A estos efectos, el Reglamento de Radiocomunicaciones precisa que el indicativo debe ser de tal naturaleza "que pueda permitir la identificación internacional sin confusión posible". Es uso tradicional de la radiodifusión que tal indicativo haga referencia a la matrícula de la emisora (por ejemplo, "EAJ ${ }^{15}-1$ ") y a su nombre ("Radio Barcelona"), ya que con estos datos queda explícita o implícitamente notificada su denominación, nacionalidad, ubicación, la identidad del concesionario, señal o sintonía característica, etc. (UIT, 1976: Art. 19 n 737).

c) Las que funcionen sin la correspondiente licencia (UIT, 1976: Art. $18 n^{\circ} 125$ ) o las que operando con ella se presentan al público confusamente haciendo creer que están instaladas en un territorio para el que, sin duda, no están autorizadas a funcionar.

Las estaciones piratas comerciales pueden encasillarse en los tres órdenes arriba citados, las políticas son básicamente del tipo b) y aunque cabe presumir que disponen de licencia en el territorio desde el que emiten, resultan internacionalmente ilícitas por falta de su frecuencia a la IFRB de la UIT. En efecto, el art. 9 $n^{\circ} 486$ del Reglamento de Radiocomunicaciones determina que "deberá notificarse a la Junta Internacional de Registro de Frecuencias toda asignación de frecuencia relativa a una estación [...] de radiodifusión, [...] b) si la frecuencia se utiliza para la radiocomunicación internacional". Es evidente que la difusión internacional de programas desde un país a la población de otro constituye una radiocomunicación internacional.

\section{LOS COMIENZOS}

Collin (1979: 11-13) afirma que "las primeras estaciones piratas fueron las que pusieron en funcionamiento los primeros alemanes opositores al nazismo, a partir

\footnotetext{
${ }^{14}$ El Art. 28 n 962, añade: "A las estaciones móviles en el mar o por encima del mar, les está prohibido efectuar servicio alguno de radiodifusión".

${ }^{15}$ De acuerdo con los usos y acuerdos internacionales del primer período de vida de la radiodifusión, a cada licencia de emisión otorgada correspondía un indicativo, compuesto por una o dos iniciales fijas para identificar el país en cuyo territorio estaba situada la estación, otra letra para representar el código admitido por cada emisora, y un número de matrícula como registro de la concesión. A España correspondieron las iniciales EA, como distintivo, y ajustó los códigos $\mathrm{J}$ y $\mathrm{R}$, el primero para las emisoras de cuarta categoría, es decir, emisoras de radiodifusión, y el segundo para las de quinta o de radioaficionados, de tal forma que EAJ-62 significa "España, estación de cuarta categoría, n 62". En otras palabras, Radio Vitoria. SEDANO LAÑO, J. Mª. El ayer de Radio Vitoria. spi. s/f.
} 
de enero de 1937, que fueron rápidamente acorralados por la Gestapo y que, a pesar de ser muy móviles, terminaron por morir al cabo de algunos meses". En mayo de 1938, otra estación emitió en la región de Horn, en Austria, exhortando a las tropas austriacas a la resistencia contra sus jefes nazis. Perseguida, la estación fue obligada a refugiarse en la frontera checa y después de los acuerdos de Múnich, la policía la acalló definitivamente.

Entre las estaciones que jugaron un papel decisivo en la lucha antifascista no es posible olvidar Radio Londres. Es cierto que la propaganda gaullista ha magnificado el papel de esta estación en su lucha contra la Alemania nazi y ha hecho de la difusión del llamamiento del 18 de junio de 1940, escuchado sólo por algunas decenas de oyentes, centenares en el mejor de los casos, un mito del que nació la resistencia francesa. Pero no es menos verdadero que estas emisiones de Radio Londres con destino a la Francia ocupada han jugado un indiscutible papel en la reconstitución de una conciencia nacional francesa, seriamente puesta en duda por las victorias militares alemanas y la propaganda nazi. Esta estación se convirtió en un verdadero órgano de enlace entre los combatientes del interior y las Fuerzas Francesas Libres de Londres. Cada día Radio Londres difundía los famosos "mensajes personales" codificados, conteniendo instrucciones para los responsables de la resistencia. El 5 de junio de 1944, "los largos sollozos de los violines" anunciaron el desembarco aliado en Normandía a los grupos locales de las Fuerzas Francesas del Interior.

\section{TIPOS DE RADIODIFUSIÓN PIRATA}

Las estaciones piratas pueden ser comerciales, políticas y libres. En este artículo nuestro objeto de estudio es la radiodifusión pirata comercial, que tiene tres características: están instaladas en buques o islas artificiales situados fuera de los territorios nacionales; su identificación no es completa porque induce o permite confusión y operan sin licencia. El objetivo prioritario de estas estaciones es el lucro. Durante los años inmediatamente posteriores a la Segunda Guerra Mundial, la radiodifusión de la vieja Europa sufrió una fuerte corriente nacionalista que presentó caracteres distintos a uno y otro lado del Telón de Acero. En el Este apareció con las formas y el estilo de su comunismo militante; esto es, subordinando el medio a las necesidades propagandísticas de su rígida política, siguiendo con ello el modelo de las emisiones soviéticas. En Occidente, su origen fue también político aunque su fin le hizo radicalmente distinto: se trataba de asegurar la neutralidad y objetividad de sus programas, tan influyentes en la opinión pública y en los estados de conciencia de las grandes masas, así como para salvaguardar los intereses económicos de una prensa obligada a plantear su financiación sobre las circunstancias más problemáticas de su historia. Para cumplir estos propósitos se dieron muy diversas fórmulas aunque, en síntesis, se utilizó la fórmula de reconocer el monopolio de las emisiones de radiodifusión a una sola empresa, pública, privada o mixta, financiada en su mayor parte por el producto de la tasa de uso y tenencia de receptores, de larga tradición y contrastada eficacia desde que este 
sistema fue implantado en el Reino Unido en 1922 para subvenir a las necesidades del servicio ${ }^{16}$. Fruto de este planteamiento fue un hecho singular en el opulento horizonte de los países ribereños de los mares Báltico, Norte y Atlántico hasta el Golfo de Vizcaya. En Noruega, Suecia, Finlandia, Dinamarca, Alemania Federal, Gran Bretaña, Holanda, Bélgica y Francia, no se dio un solo caso, en las décadas de los años cuarenta y cincuenta, de emisoras de radiodifusión o televisión que difundieran programas, mensajes o cuñas publicitarias comerciales. Sobre este fondo apareció un nuevo y lucrativo negocio.

En efecto, en el mes de agosto de 1958, según la revista Life Internacional, nació la primera estación pirata de radio en Europa, instalada en el mar y que fue iniciativa de una mujer sueca, la señora Britt Waduer quien, en 1958, compró un barco y comenzó a emitir programas radiofónicos en competencia con el monopolio de radiodifusión en Suecia. El país puso fuera de la ley este procedimiento en 1962 y encarceló a la señora Waduer en 1964. Los admiradores de la dama inundaron la celda de ésta con frutas y flores, y organizaron manifestaciones callejeras que casi degeneran en tumultos pidiendo libertad.

Durante el mismo 1958, la costa danesa del estrecho de Sund, y especialmente Copenhague, se vio cubierta por unas emisiones radiofónicas, en onda media, difundida desde un pequeño buque anclado en el estrecho que separa Suecia de la isla danesa de Zealand, el paso más frecuente del Báltico al Norte, sumamente angosto entre el castillo de Elsinor y la ciudad sueca de Hälgsingborg y más abierto entre Copenhague y Malmoe. Las emisiones eran alegres, principalmente dirigidas a la juventud, patrocinadas por marcas multinacionales y danesas. Como la nave se encontraba en aguas internacionales y las leyes del mar protegen la navegación de buques abanderados -y el portador de la emisora lo estaba- nada podía hacer el gobierno danés para impedir aquellas emisiones que ponían en entredicho el monopolio no mercantil de la Danmarks Radio. Poco después, otro estrecho internacionalizado, el Gran Belt, sirvió de base a Radio Mercur ${ }^{17}$, que "Un año después [...] tenía unas entradas publicitarias de ciento cincuenta mil dólares" (Rodrigo y Ruiz, 1981: 268; Gaido: 1981: 172) y se trataba de otra emisora "pirata" comercial dedicada a la audiencia danesa en general y en especial a Odense y Aarhus.

\footnotetext{
${ }^{16}$ La licencia de recepción fue impuesta, a título experimental, por el Postmaster General en julio de 1922, antes de que se constituyera la British Broadcasting Company Ltd. el 18 de octubre de 1922 y fueran ofrecidas en pública suscripción sus 100.000 acciones de una libra esterlina. Las primeras emisiones de la BBC salieron al aire el 14 de noviembre del mismo año. La Compañía fue registrada el 15 de diciembre y la licencia del Post-Office, con injustificado retraso, no fue concedida hasta el 18 de enero de 1923. En ella quedó confirmada la imposición de la tasa de recepción y su destino para el mantenimiento del servicio por la compañía exclusivista. La BBC Corporación, sucesora de la BBC Compañía, estuvo amparada por Carta Real, otorgada el 12 de noviembre de 1926 con efectos de $1^{\circ}$ de enero de 1927 (Briggs: 1961: 123-134; Black, 1972: 13-22).

${ }^{17}$ Consultar www.radio-mercur.dk. Emitió de 1958 a 1962 en 88.00 MHz. Lamentablemente la página está en danés, pero es muy completa sobre la historia de la emisora y se pueden escuchar programas realizados en aquella época. También en inglés en http://www.cwgsy.net/private\%2Foffshorepirateradio/ mercur.html;

http://icce.rug.nl/soundscapes/DATABASES/RP2/Scandinavian offshore radio.shtml y http://icce.rug.nl/soundscapes/DATABASES/RP2/Mercur01.shtml.
} 
El descubrimiento estaba hecho, el éxito asegurado, la audiencia conquistada -la realización radiofónica europea se hallaba dormida sobre el colchón de plumas de los monopolios nacionales- y los anunciantes satisfechos del impacto y de los ecos de las sugestivas cuñas publicitarias lanzadas al aire por los locutores más animados de la radiodifusión nórdica. En aquellas circunstancias, nacieron múltiples continuadores e imitadores. Toda una filosofía no desaparecida después de dieciocho años y tuvo que crearse un preciso andamiaje legal para destruirlas.

Otras estaciones importantes, de las diez que flanquean las Islas Británicas fueron Radio London, Radio England, Britain Radio y R. 390 (Cuadernos de Documentación, 1969).

Radio London operaba a bordo de un barco a lo largo de la costa del sureste de Inglaterra. Apareció en diciembre de 1964, emitía en $1125 \mathrm{kHz}$. y después en $1129,5 \mathrm{kHz}$. La potencia de la estación era del orden de $20 \mathrm{kw}$, aunque según algunas informaciones se dobló la potencia. Ocasionaba grandes perturbaciones en dos estaciones belgas de $1124 \mathrm{kHz}^{18}$.

R. 390 fue visitada por el reportero jefe de la oficina de Life en Londres Jim Hicks. La estación estaba situada a nueve millas de la costa, pasados los criaderos de ostras del estuario del Támesis y se alberga en un fuerte espigón de hormigón y acero abandonado que fue un puesto de defensa en la Segunda Guerra Mundial. Ahora es la sede de esta emisora con los riesgos de vida en el mar y es peligrosa a la vez que aburrida. La tripulación tiene que estar inmunizada contra el mareo, permanece dos semanas a bordo por una en tierra de permiso, "no hay bebida ni mujeres. (Cuando alguna joven cantante popular visita una embarcación pirata y no puede marcharse a causa del mal tiempo, se encierra con cerrojo en su cabina)" (Cuadernos de Documentación, 1969).

Radio England y Britain Radio están financiadas por un sindicato de norteamericanos, canadienses y británicos, comenzaron a actuar con la sintonía The Yelow Rose of Texas ("La rosa amarilla de Texas"). Los compañeros de Colin Nicol, director de Radio England, que antes trabajó en Radio Caroline y Britain Radio, ambas piratas, como se sabe, eran cuatro norteamericanos sureños, dos ingleses y dos australianos como operadores. El total de la tripulación estaba formado por un gato siamés y 13 marineros procedentes de Nicaragua, El Salvador, Colombia, Jamaica, España y Cuba. Los operadores, Ilamados disc jockeys están seis horas diarias "en el aire", pasan otra hora firmando autógrafos en postales y muchas horas realizando lecturas obligadas: "Cashbox", "Billboard" de los Estados Unidos y "Musical Express" de Inglaterra. Adornan las cabinas de los dics jockeys fotografías de desnudos" (Cuadernos de Documentación, 1969).

De la importancia que tuvieron estas estaciones da idea que 30.000 chicas se compraron pestañas postizas sólo porque una estación pirata les dijo que lo hici-

\footnotetext{
${ }^{18}$ Consejo de Administración de la UER. Ginebra: 20 al 22 de mayo de 1965.
} 
eran. Los jóvenes preferían los discos de Radio London a los programas solemnes de la BBC, aunque, a menudo, estos fueran tapados por aquellos y hubiera un auténtico caos del éter (Cuadernos de Documentación, 1969).

El mayor negocio de las emisoras privadas se realiza en Gran Bretaña, donde entre los anunciantes figuran "Unilever" y la "Internacional Publishing Corporation". Los beneficios son tan importantes que atraen incluso dinero de Texas. "La piratería es un enorme negocio" (Cuadernos de Documentación , 1969). Radio London gana más de un cuarto de millón de dólares al mes; Radio Caroline cien mil dólares" (Cuadernos de Documentación, 1969) ${ }^{19}$.

"Las emisoras piratas inglesas tienen su cuartel general en Londres, para organizar su discoteca y su publicidad" (Cuadernos de Documentación , 1969):

Los piratas prefieren llamarlas 'emisiones comerciales independientes'. Cierto número de grandes anunciantes y la mitad, al menos, de la población de Inglaterra, apoyan a los piratas. Paul Bryan, el diputado Tory que lleva este asunto dijo: < Veinte millones de oyentes tienen derecho a protestar por la prohibición de estas emisoras, si no se hace un intento eficaz para proporcionarles una oportunidad a sus programas> (Cuadernos de Documentación , 1969).

El Gobierno ha prometido un "Libro Blanco" con proyectos de cambios para satisfacer los gustos del público, pero en el interior la inclinación popular a favor de las radios piratas sigue aumentando. En cualquier caso, algunas emisoras no están dispuestas a rendirse. Radio 390, dos de cuyos representantes fueron citados a juicio, dijo: "Tratamos de dar la batalla y de llevar el caso ante el más alto Tribunal de este país. Creemos que la torre (donde está emplazada la emisora pirata) está fuera de la jurisdicción de ningún magistrado" (Cuadernos de Documentación , 1969).

En realidad se trataba de un problema muy complejo pues, por un lado, la Conferencia sobre la Libertad de Información de las Naciones Unidas celebrada en Ginebra en 1948, proclamó que la propagación de las ondas de radio ignoran las fronteras nacionales, pero al mismo tiempo se comprendía la necesidad de organizar el espectro radioeléctrico para evitar las interferencias de unas estaciones sobre otras, por lo que era necesario someter las ondas a unas estrictas regulaciones internacionales que son de todos conocidas y que se encuentran en los Reglamentos de Radiocomunicaciones de la Unión Internacional de Telecomunicaciones (UIT).

Los argumentos en pro descansaban en el pasado de la radiodifusión continental europea, en la realidad americana, en la legitimidad y conveniencia de la libre competencia en la mayoría de las actividades humanas, en los atractivos de la iniciativa privada, en los principios de libertad de la información y en la no siempre

\footnotetext{
${ }^{19}$ Para ampliar la información sobre esta estación se puede consultar Millecanali $\mathrm{n}^{\circ} 16$ (Aprile 1976) y la pagina web www.radiocaroline.co.uk/default.aspy.
} 
justificada razón del antidemocrático monopolio. Ningún radioescucha creyó ilícita la actividad de aquellas alegres emisoras capaces de cubrir su tiempo de ocio mejor que los aburridos programas de las cadenas oficiales.

El procedimiento, con algunas variantes impuestas por circunstancias locales, era casi siempre el mismo: una compañía integrada por socios de diversas nacionalidades de identidad nunca proclamada adquiría o alquilaba un pequeño barco (generalmente, un antiguo pesquero) de bandera no europea (liberiana, panameña, etc.). En él instalaban un pequeño transmisor en onda media y cualquier frecuencia, con antena y potencia suficiente para cubrir una población importante (Londres, Copenhague, Estocolmo, Rotterdam) o con mayor potencia para cubrir el área formada por el triángulo Londres-París-La Haya, con audiencia potencial de veinte millones de escuchas, altamente atractiva para la publicidad. Los programas, realizados en un alejado centro de producción instalado en tierra firme, eran enviados en cinta magnética al buque.

En los primeros años de la experiencia 'pirata', los buques dejaban de emitir tan pronto entraban en aguas territoriales para repostar, limpiar fondos o cambiar de tripulación y cuando las autoridades se decidieron a prohibir aquella actividad, quedaron los buques anclados (en el Canal de la Mancha se emplearon también islas artificiales construidas sobre bajos marinos en la guerra para vigilancia de costas) y eran pequeñas embarcaciones las dedicadas a las funciones de trasiego de cintas, víveres, combustible, cambio de tripulación, etc. Si por avería o temporal el buque portador se veía obligado a entrar en aguas jurisdiccionales y era apresado, todo lo que sus propietarios perdían era material sustituible por valor equivalente a los ingresos publicitarios de dos meses. La adquisición de otro buque y otro transmisor permitía reanudar la explotación.

\section{CONCLUSIONES}

A las estaciones piratas se debe, también, el renacimiento de la radiodifusión, propio de nuestra época. Cuando después de la Segunda Guerra Mundial se desarrolló en Europa la televisión, las estaciones nacionalizadas consideraron contados sus días. Un desánimo, un abandono radical pareció calar entre directivos, ejecutivos, programadores y realizadores. Pareció morir la creación, la imaginación. Sólo algunas emisoras aisladas, de carácter comercial, como Luxemburgo, Montecarlo, Europa $n^{\circ} 1$ y Andorra, entre las internacionales, y pequeños grupos de estaciones españolas y portuguesas, también animadas por necesidades mercantiles, se enfrentaron a la todopoderosa televisión.

Allí donde la televisión cerraba su programación, estaba la radio, con programas matutinos para la mujer, seriales y musicales vespertinos y emisiones de madrugada destinadas a cuantos profesionales deben permanecer despiertos. Las estaciones piratas fueron a la conquista de otro tipo de audiencia, el de la juventud, de espaldas a la realidad oficial. Creó el nuevo estilo que pronto copiarían las grandes emisoras legales y comerciales de los pequeños países y, bastante 
más tarde, las segundas y terceras cadenas de las redes monopolísticas de los países occidentales. Ese nuevo estilo ha calado ya en toda la radiodifusión.

En el marco de los convenios y de los reglamentos internacionales vigentes, la radiodifusión pirata es ilegal por su origen, naturaleza y destino de sus programas. Sin embargo, estas emisoras han creado un novísimo estilo radiofónico, atractivo para la generalidad de los oyentes y apasionante para la audiencia juvenil. Para las estaciones piratas el ritmo es el mensaje. Música pop muy del tiempo, publicidad dosificada hasta el máximo soportable y noticias deportivas es la fórmula magistral de su programación durante las 24 horas del día, mantenida por contacto directo del locutor-presentador con su audiencia.

\section{REFERENCIAS BIBLIOGRÁFICAS}

AGUILERA, M. (1985): Radios libres y radios piratas. Madrid: Forja.

BLACK, P. (1972): The Biggest Aspidistra in the world. London: BBC.

BRIGGS, A. (1961): The History of Broadcasting in the United Kingdom. Oxford: University Press. Vol 1:"The Birth of Broadcasting". 1961. Vol 2: "The Golden Age of Wireless". 1965. Vol3: "The War of wors". 1970

BROWNE, Don R.: "The BBC and The pirates: a Phase in the Life of a Prolonged Monopoly". Journalism Quartely. (Spring. 1971).

COLLIN, C.: "Ecoutez la vrai difference". La pensée sauvage, Enero 1979, pp. 11 -13.

COSTA, J.M.: "De Radio Caroline, que emitía desde un barco sólo ha quedado un canario. Desaparece bajo el mar la última emisora pirata de música pop". El País, 22 Marzo 1980.

CRIEL, T.: "Mi amigo op de spaanse radiotoer". Gazet van Antwerpen, 25 Février, 1975. CUADERNOS DE DOCUMENTACIÓN. Escuela Oficial de Radiodifusión y Televisión. (Mayo 1969).

GAIDO, M.: Los orígenes: la FM, los disk-jockeys y las radios piratas. En AA.VV. (1981):

De las ondas rojas a las radios libres. Barcelona: Gustavo Gili, pp.172-173.

DEBBASCH, Ch. (1967): Traité de droit de la radiodifusión. Paris. Ed. L.G.D.J.

DOVKANTS, K.: "Radio pirates booming". Evening Standard, 9 August 1984.

EMERY, W. B. (1969): National and International Systems of Broadcasting. Michigan: University Press.

EVEN, M.: "Les malheurs d'un pirate. Revoici Caroline". Le Monde, 22 Decembre1975.

HANSSON, G.: Révision de la loi suédoise concernant les stations "pirates". Revue de I'UER, no 101 (Janvier 1967). HOPKINS, A.: "Radio Caroline Goes Down in Force 9 Gale". Daily Telegraph, 21 march 1980, pp.8-9.

IEZZI, F.: "TV Piracy on the High Seas". Television Quartely, n IV (Winter 1965). 
KNOT, H.: "Rare pictures from radio's past Scandinavian Offshore Radio". Soundscapes. (Avril 1999), Vol. 2. También se puede consultar en línea. [Consulta 2 febrero 2008] < http:// icce.rug.nl/soundscapes/DATABASES/RP2/Scandinavian_offshore radio.shtml>

LABORDE, E.: "Londres: Hoy serán clausuradas las emisoras pirata". La Vanguardia, 15 Agosto 1967.

McLEOD, N.: "The problem with pirates". Broadcast Sound (July/August 1984).

NAMUROIS, A.: "La répression des activités des stations pirates de radiodiffusion". Revue de I'UER, n 90 (Mars 1965).

PAULU, B. (1968): Radio and Television Broadcasting on the European Continent. $2^{\mathrm{a}}$ edición. Minneapolis: University of Minnesota Press.

PEZUELA, A.: "Gran Bretaña era la última emisora pirata. Se hundió Radio Caroline". Pueblo, 21 marzo 1980.

PUJADES, P.: "Radio 'Mi Amigo' tiene su base en Platja d'Aro. Radio pirata 'legal' y única”. Tele-Expres, 30 agosto 1977.

REMES, K.: "Répression d'emissions à partir de l'île artificielle. Loi néerlandaise sur les instalations en mer". Revue de l'UER, nº 90 (Mars 1965).

ROBBINS, E. C.: "Déclin des pirates. La situation britannique que évolue". Revue de l'UER, $\mathrm{n}^{\circ} 106$ (Novembre 1967).

RODRIGO, M.; y RUIZ-COLLANTES, X.: Cronología. En AA.VV. (1981): De las ondas rojas a las radios libres. Barcelona: Gustavo Gili, pp. 268-269.

SEDANO LAÑO, J. Mª: El ayer de Radio Vitoria. spi. s/f.

SETON, C.: "Sea silences original pirate station". The Times, 21 March 1980.

SNODDY, R.: "Transmitter on, Alice is go...". Financial Times, 9 April 1983.

UER: diferentes documentos del Consejo de Administración y de la Asamblea General.

UIT (1976): Reglamento de Radiocomunicaciones. Anejo al Convenio Internacional de Telecomunicaciones. Ginebra: Ed. Secretaría General de la UIT.

\section{Breve semblanza biográfica de los autores}

Francisco José Montes Fernández es Doctor en Periodismo y licenciado en Comunicación Audiovisual. Ha impartido docencia en la Facultad de Ciencias de la Información de la Universidad Complutense de Madrid (España), desde el mes de octubre del año 1976 hasta el día de hoy. Ha sido Director Técnico de la Universidad Nacional de Educación a Distancia (UNED) cinco años. Desarrolló su vida profesional como Titulado Superior en Radiotelevisión Española desde 1972 hasta 2007 cuando fue prejubilado.

Javier Sierra Sánchez es Director de la titulación de Publicidad y RR.PP. en la Facultad de Comunicación de la Universidad San Jorge de Zaragoza. Doctor cum laude por unanimidad en Ciencias de la Información (Comunicación Audiovisual y Publicidad) Universidad Complutense de Madrid. Licenciado en Comunicación Audiovisual y Periodismo por la UCM. Profesor de Teoría de la Comunicación y Teoría de la Información de 
la Facultad de Ciencias de la Comunicación de la Universidad San Jorge de Zaragoza. Profesor de Comunicación e información audiovisual I en la Universidad Abat Oliba CEU. Máster en Gestión de Calidad por la Escuela de Organización Industrial en colaboración con el Ministerio de Ciencia y Tecnología. Experto en Relaciones Públicas Internacionales por la Universidad Complutense de Madrid. Experto en Ceremonial y Protocolo del Estado e Internacional por la Escuela Diplomática de Madrid y la Universidad de Oviedo.

(Recibido el 27-02-2008, aceptado el 01-03-2009) 